\title{
CONHECENDO MAIS SOBRE A LUDICIDADE, FORMAÇÃO DE PROFESSORES E ENSINO DE MATEMÁTICA NO CURSO DE PEDAGOGIA DA UFSCAR
}

\author{
AMÉRICO JUNIOR NUNES DA SILVA \\ Universidade do Estado da Bahia \\ CÁRMEN LÚCIA BRANCAGLION PASSOS \\ Universidade Federal de São Carlos
}

RESUMO Este artigo, recorte de tese de doutoramento, objetivou caracterizar as propostas presentes nos documentos de constituição do curso de Pedagogia da UFSCar, quanto à ludicidade e ao professor que ensinará matemática, nos anos iniciais, para entender o lugar que essas questões ocupam no curso. Para isso, respaldamo-nos nos pressupostos de uma pesquisa narrativa, elegendo-a como a melhor forma de compreender a experiência e abraçando as narrativas, simultaneamente, como método e como fenômeno a ser estudado. Essas narrativas foram analisadas, portanto, tendo em vista o seguinte movimento narrativo: olhar ao que propõe o curso de Pedagogia da UFSCar em busca de indícios de como se dá essa formação e como foi significada pelas estudantes. Foi a partir do olhar para o Projeto Pedagógico que percebemos que há uma supervalorização de um perfil específico de formação. Pelo histórico do curso e sua ligação, desde a criação, com as questões de orientação e administração escolar, e pelo que nos apresentaram as estudantes, notamos que se priorizou um determinado aspecto da formação em detrimento de outros. Uma maior preocupação com a formação do professor que ensinará matemática nos anos iniciais e a sua formação lúdica, por exemplo, foram silenciadas no documento.

Palauras-Chave: Formação inicial. Ensino de matemática. Anos iniciais. Ludicidade. Narrativas. 


\section{COURSE}

This article, recontation of doctorate, aimed to characterize the proposals present in the training documents of the UFSCar Pedagogy course regarding playfulness and the teacher who teaches mathematics in the initial years and the meaning of the place that is occupied without a course. For this, therefore, he must support us in a narrative experience, choosing it as a method of understanding and experience as narratives, both as method and as a being studied. These narratives were analyzed, therefore, considering the following narrative exercise: i) Look for the UFSCar Pedagogy course in search of a training exercise as if it were meant by the students. It was a research project that emphasizes the overvaluation of a specific training profile. By the history of the course and its connection, as its creation, with the issues of guidance and school administration and why it is as good as the students, it was noted that they had already assumed the role of training over others. For example, the major problem for the teacher training that teaches mathematics in the early years and its playfulness has been silenced from the document. Keywords: Initial formation. Mathematics teaching. Initial years. Playfulness. Narratives. DE PROFESORES Y ENSEÑANZA DE MATEMÁTICA EN EL CURSO DE PEDAGOGÍA DE LA UFSCAR

Este artículo, recontación de doctorado, objetivó caracterizar las propuestas presentes en los documentos de formación del curso de Pedagogía de la UFSCar en cuanto a la ludicidad y al profesor que enseña matemáticas en los años iniciales y el significado del lugar que esta ocupada sin curso. Para ello, por lo tanto, debe apoyarnos en una experiencia narrativa, eligiéndola como un método de comprensión y experiencia como narrativas, simultáneamente, como método y como un ser estudiado. Estas narraciones fueron analizadas, por lo tanto, teniendo en cuenta el siguiente ejercicio narrativo: i) Mirar al curso de Pedagogía de la UFSCar en busca de un ejercicio de formación como si fuera significada por los estudiantes. Fue un proyecto de investigación que enfatiza la sobrevalorización de un perfil específico de formación. Por el historial del curso y su conexión, como su creación, con las cuestiones de orientación y administración escolar 
y por lo que es tan bueno como los estudiantes, se notó que ellos ya habían asumido el papel de la formación en detrimento de otros. El mayor problema para la formación del profesor que enseña matemáticas en los años iniciales y su formación lúdica, por ejemplo, fueron silenciadas del documento.

Palabras Clave: Formación inicial. Enseñanza de matemáticas. Años iniciales. Alegría. Narrativas.

\section{Introdução}

Para escrevermos este artigo, tivemos como norteadores da escrita caracterizar as propostas presentes nos documentos ${ }^{1}$ de constituição do curso de Pedagogia da UFSCar, quanto à ludicidade e ao professor que ensinará matemática nos anos iniciais, tendo em vista entender o lugar que essas questões ocupam no curso.

Achamos, desde o princípio, que esse olhar mais analítico ao que propõe o curso de $\mathrm{Pe}$ dagogia da UFSCar, sobre a ludicidade e a formação do professor que ensina(rá) matemática nos anos iniciais, seria importante, por nos apresentar indícios de como se dá essa formação e, em consequência, algumas de suas possiveis implicações para a significação das experiências ${ }^{2}$ pelas estudantes.

Concordamos com Rocha (2005), que todo programa de formação inicial ${ }^{3}$ de professores

1 Consideramos como documentos de constituição: i) Projeto Pedagógico (PP) do Curso de Pedagogia da UFSCar; ii) Documentos oficiais que serviram de referência para a construção do PP; iii) Projetos de pesquisa e extensão realizados durante o período em que os sujeitos da pesquisa estavam matriculados; e iv) Planos de curso de disciplinas.

2 Segundo Larrosa Bondía (2002, p. 21), “é o que nos passa, o que nos aconteceu, o que nos toca. Não o que se passa, não o que acontece, ou o que toca. A cada dia se passam muitas coisas, porém, ao mesmo tempo, quase nada nos acontece".

3 Tomamos por formação inicial, portanto, o primeiro momento que prepara o sujeito para ingressar na profissão. De acordo com as Diretrizes Nacionais para a Formação Inicial de Professores (BRASIL, 2001), essa formação precisa ser entendida e vivenciada como um espaço que ensine o futuro professor a aprender de modo contínuo e reflexivo (PIMENTA, 1996) e é no momento inicial da formação que o estudante começa a ver-se como professor, permitindo-se construir tem, de um modo explícito ou implícito, um modelo e/ou perfil de professor que se pretende formar. Esperamos entender, a partir do olhar para o curso, justamente isso.

Muitas pesquisas que buscaram investigar o curso de Pedagogia fizeram esse percurso, olhando para os documentos que o constituem. Pensamos em fazer isso, antes mesmo de constatarmos essa prática que, para nós, é realmente importante. Assim, o que difere o percurso que estabelecemos, nesse momento, com o que foi feito nas demais pesquisas? Além de nosso olhar, claro, que confere uma leitura diferente das demais, focalizamos as experiências e as suas marcas, a partir das estudantes.

As leituras feitas nos permitiram mergulhar em uma realidade "teórica" que pode, ou não, a partir de nossas experiências e envolvimento, por dois anos, com as participantes da pesquisa, corroborar a realidade que é diariamente vivenciada pelas futuras professoras. Nesse caso, portanto, traremos, neste artigo, também o que as estudantes revelaram, em seus diá-

\footnotetext{
sua identidade docente. É importante considerar, antes de tudo, que os estudantes chegam ao início de sua formação trazendo concepções sobre o que é ser professor, muitas vezes resultantes das marcas deixadas pelas experiências vividas, positivas ou negativas, a depender da forma como tudo isso foi trabalhado e significado por eles. A formação inicial, como nos apresenta Oliveira (2011), "não pode abdicar de oferecer espaço e tempo para a deliberação sobre o ensino que se deseja desenvolver, para a justificativa das opções feitas e análise do confronto das escolhas e da ação desenvolvida e das aprendizagens dos alunos".
} 
rios $^{4}$ e nas entrevistas narrativas, a respeito das experiências propiciadas, seja nas três disciplinas acompanhadas, como nas demais atividades propostas, ao longo do curso, no que tange ao nosso puzzle $e^{5}$ de pesquisa.

\section{Percurso metodológico adotado}

Este artigo é um recorte de nossa pesquisa de doutoramento, vinculada ao Programa de Pós-Graduação em Educação da Universidade Federal de São Carlos (UFSCar), intitulada: "Querido diário... o que revelam as narrativas ${ }^{6}$ sobre ludicidade, formação e futura prática do professor que ensina(rá) matemática nos anos iniciais".

Nossa pesquisa, portanto, articulou-se à pesquisa narrativa, ${ }^{7}$ sobretudo pela necessidade de entender a importância da história e das marcas de vida, sob o processo de formação inicial e a futura prática docente. Tem como foco as experiências e as diversas aprendizagens delas oriundas. Trata-se, portanto, de uma pesquisa qualitativa.

De uma forma geral, a tese que resultou na escrita deste artigo focaliza as narrativas produzidas ao longo da formação pelas participantes da pesquisa. Além de investigar o que

4 Pois é, temos aqui, na figura do diário, como nos apresentou Clandinin e Connelly (2015, p. 145), um “meio poderoso para que as pessoas possam dar relatos de suas experiências". Os diários talvez, e muitas vezes, assumem "uma qualidade questionadora intimamente reflexiva, talvez menos como uma forma de relato de experiência, como observado por Sarton, e mais como uma forma de problematizar a experiência" (2015, p. 146).

50 que revelam narrativas de licenciandos do curso de Pedagogia, construídas ao longo da formação, sobre a ludicidade, o ensino de matemática e o constituir-se professor que ensina matemática nos anos iniciais.

6 "A narrativa, por suas características, é uma forma de utilizar a linguagem nos processos que organizam a vida e as experiências vividas". (MAFFIOLETTI, 2016, p. 52)

7 A pesquisa narrativa, como nos apresentam Clandinin e Connelly (2015), é uma das formas de compreender a experiência e dá-se por meio de colaboração entre o pesquisador e os participantes, ao longo de um tempo, com um lugar ou série de lugares, e em interação com o milieus. revelam essas narrativas sobre a ludicidade, o ensino de matemática e a constituição do professor que ensina(rá) matemática nos anos iniciais, buscamos entender como a construção desses diários e a anamnese de suas vidas podem ter sido formativas e contribuído na constituição da identidade docente ${ }^{8}$ das participantes.

Participamos deste estudo 9 , eu (o pesquisador $\left.{ }^{10}\right)$, minha orientadora, a professora Cármen e cinco estudantes ${ }^{11}$ do curso de Pedagogia da UFSCar, que aceitaram, assinando o Termo de Consentimento Livre e Esclarecido (TCLE), participar de forma voluntária. Foi critério de escolha dos participantes que os estudantes estivessem matriculados, no segundo semestre de 2015, na disciplina "Matemática: conteúdos e seu ensino" e que, no semestre seguinte ao da realização do início da pesquisa, cursassem as disciplinas "Metodologia do Trabalho Docente nos anos iniciais do Ensino Fundamental Regular" e "Prática de Ensino e Estágio Docente nos anos iniciais do Ensino Fundamental Regular".

As experiências propostas ao longo das três disciplinas e nossa participação durante

8 Dessa forma, percebemos, nesse momento, a construção da identidade docente não como um dado adquirido, uma propriedade, um produto, mas como um processo (NÓVOA, 1992). De acordo com Pimenta (1999), a identidade docente constrói-se a partir da significação e reafirmação social e cultural da prática/ profissão, do confronto entre as teorias e as práticas, da análise sistemática das práticas em conjunto com as teorias existentes, da construção de novas teorias.

9 A pesquisa de doutoramento foi aprovada pelo Comitê de Ética por meio do parecer 1.697.334, número CAAE 53374116.0.0000.5504.

10 A inserção possibilitada pelo espaço propiciado no Programa de Estágio Supervisionado de Capacitação Docente (PESCD), coloco-me, com esta pesquisa, na posição do professor-pesquisador que, estando totalmente envolvido em sua prática - e justamente por estar envolvido - levanta constantes questionamentos acerca de suas ações, a fim de encontrar caminhos para o melhor desempenho de suas atividades de formação e de seus pares e, assim, contribuir para a melhoria da educação. É, portanto, em busca de melhorias para o campo educacional, que volto o meu olhar para esse espaço, percebendo-o como um espaço de pesquisa e formação.

11 Hilda, Gabriela, Emily, Maria e Elisa. 
todo esse processo compuseram os nossos diários: das participantes e do pesquisador. Nesses diários, registramos nossas experiências, impressões e angústias. Enquanto pesquisadores, fizemos observações sobre as falas e posicionamentos das estudantes e outras questões relacionadas à pesquisa, que consideramos relevantes para a construção do texto de pesquisa.

É preciso ouvir o que os licenciandos têm a nos dizer sobre as suas vivências. Entender esse movimento, a partir dos lampejos da história de vida dos participantes da pesquisa, poderá permitir aprendizagens, tanto aos licenciandos quanto ao formador de professores, e, consequentemente, revelar elementos importantes para (re)pensar os cursos de formação de professores.

Para este artigo, focaremos apenas em caracterizar as propostas presentes nos documentos de constituição do curso de Pedagogia da UFSCar quanto à ludicidade e à formação de professores que ensinarão matemática. Para isso, portanto, realizaremos o seguinte percurso:

Identificar, nos documentos de constituição do curso de Pedagogia da UFSCar, indícios das concepções ${ }^{12}$ de ludicidade, formação de professores e ensino de matemática.

E como serão feitas as análises? Compreendemos, concordando com o que nos apresenta Crecci (2016), que a análise e a interpretação precisam levar em consideração um processo tridimensional, envolvendo temporalidade (diacronia), interações pessoais e sociais e o lugar (cenário) onde se situa o fenômeno a ser

\footnotetext{
12 Entendemos, nesse momento, fundamentando-nos em Cury (1999, p. 37), que as concepções são conjuntos de ideias, construídas a partir das experiências que as pessoas tiveram, do seu meio escolar, por exemplo, "do conhecimento que construíram, das opiniões de seus mestres, enfim, das influências socioculturais que sofreram durante suas vidas, influências essas que se vêm formando ao longo dos séculos, passando de geração a geração [...]".
}

investigado e narrado. Tudo isso precisa estar presente no momento da escrita do texto de pesquisa. A análise, portanto, precisa ser entendida como uma forma de construir sentidos a partir das narrativas das experiências apresentadas pelas participantes da pesquisa. Para isso, tendo em vista a perspectiva diacrônica, tomamos como referência nossa própria experiência, ao longo da convivência no curso de Pedagogia, com as cinco participantes, durante dois anos.

\section{Problematizando o Projeto Pedagógico a partir das experiências}

Lemos o Projeto Pedagógico (PP) algumas vezes, ao longo desses quatro últimos anos. Desse exercício de leitura ficava, sempre, uma infinidade de questionamentos que, pensávamos, seriam ampliados à medida que a experiência acontecesse. Hoje, após as disciplinas de "Matemática", "Metodologia" e "Estágio", o revisitamos para alimentar nossas provocações que, na verdade, nunca foram apenas nossas. Percebemos, pois, ao longo de suas escritas e falas, que as estudantes trazem consigo algumas delas.

O que faremos agora? Uma provocação, querido leitor. Que fique claro, portanto, que, nesse primeiro momento, nosso intuito é alimentar alguns questionamentos que tivemos durante as leituras do PP do curso de Pedagogia da UFSCar. É isso, justamente, o que faremos: traremos nossas provocações e criaremos um paralelo entre a leitura da proposta e a significação da experiência pelas estudantes.

Levantamos, dessas nossas leituras, alguns elementos que, para nós, se configuraram como pontos de partida para a discussão. Foram questões que nos inquietaram no momento da leitura e que, claro, gostaríamos de socializar e discutir com vocês. 
Nessas leituras do PP do curso, tendo em vista o olhar para o documento, a partir de nosso puzzle de pesquisa, nos inquietou: a) a diminuta preocupação com a formação matemática do futuro pedagogo; b) a carga horária insuficiente para o trabalho com essa ciência; c) a inexistência de uma discussão consistente sobre ludicidade; e d) a organização do estágio de alfabetização antes da disciplina de matemática. Esperamos que você, leitor, pense conosco sobre esses pontos e que nos ajude a ampliar alguns deles, a partir de seu olhar, história de vida e experiências. Vamos lá?

o nosso primeiro contato com o curso de Pedagogia da UFSCar, para a realização desta pesquisa, aconteceu na disciplina de "Matemática: conteúdos e seu ensino", durante o segundo semestre do ano de 2015. Submetemos a proposta de trabalho ao Programa de Estágio Supervisionado de Capacitação Docente (PESCD) e articulamos o mesmo com a produção de dados para a pesquisa.

À medida que conhecíamos o curso e tínhamos contato com as estudantes da disciplina, que mais tarde aceitaram participar da pesquisa, fomos observando que algumas dificuldades, também destacadas por Gatti (2010),13 por exemplo, se mantinham, como nos cursos com carga horária inferior. Daí nos veio, antes mesmo de começar o trabalho na disciplina, a curiosidade de conhecer a proposta de criação do curso. Decidimos procurar informações a esse respeito. Por quais motivos fizemos essa busca? Bom, na verdade, consideramos importante considerar essa gênese, principalmente para entender os motivos de algumas escolhas e caminhos de formação percorridos atualmente.

Não conseguimos muitas informações a esse respeito, mas, em consulta ao Projeto Pe-

13 Embora tenhamos falado deles anteriormente, achamos interessante trazê-los aqui: a desarticulação teoria e prática e o pouco tempo destinado ao ensino de matemática, por exemplo, são alguns deles. dagógico (SÃO CARLOS, 2012), descobrimos que o curso de Pedagogia da UFSCar, um dos primeiros da instituição, foi implantado em 1971, com Habilitação em Orientação Educacional e seguido pela Habilitação em Administração Escolar; ambos foram reconhecidos em 1974 pelo Conselho Federal de Educação. Percebemos, pelas duas habilitações apresentadas, que o curso, quando de sua criação, atendia à lógica de formação de um perfil que não era o de docente..$^{14}$

Tendo em vista o movimento de repensar os cursos de Pedagogia, sobretudo no Estado de São Paulo, de modo a aproximá-los das questões da docência, foi proposta, em 1988, uma reformulação substancial do curso, como nos apresenta ainda o documento. E essa reformulação não tirou o foco da formação de orientadores e administradores escolares; ${ }^{15}$ apenas em 2004, segundo o documento (SÃO CARLOS, 2012), houve a extinção das habilitações e a tentativa de formar o que eles chamavam de "Pedagogo Pleno".

Somente a partir de 2004, com a extinção das antigas habilitações, há uma maior aproximação desse perfil. No entanto, foram muitos anos de curso em que a prioridade formativa foi a orientação e a administração escolar. Isso, de certo modo, não deixou marcas no percurso formativo, que até hoje perduram no curso? ${ }^{16}$

Em 2007, uma comissão criada para pensar o projeto pedagógico teve o cuidado de incorporar, na (re)formulação, as reivindicações feitas pelos discentes, por meio das assembleias periódicas de avaliação dos semestres letivos. Observamos, como propostas aponta-

14 A professora Cármen achou importante destacar e informar a você, querido leitor, que a formação de professores para atuar nos anos iniciais, naquele período, ocorria nos cursos de nível médio: Magistério.

15 Vale lembrar que em 1988 são criados, pela Secretaria da Educação do Estado de São Paulo, através do Decreto 28.089/88, os Centros Específicos de Formação e Aperfeiçoamento do Magistério - CEFAM.

16 Lembre-se dessa passagem, caro leitor. Retomarei essa questão mais a frente, tá? 
das, a "flexibilização da matriz curricular; ausência de disciplinas e estágios voltados para a educação infantil e à educação de jovens e adultos" e "maior integração nos estágios bem como no trabalho com os créditos práticos" (SÃO CARLOS, 2012, p. 8).

Dentre as questões apresentadas pelos docentes e estudantes do curso, no documento, observa-se que não figuram, enquanto preocupações, as questões da formação do professor que ensinará matemática nos anos iniciais, por exemplo, ou algo que nos remeta a uma preocupação com o conhecimento da matemática e das demais áreas do conhecimento que são ensinadas nos anos iniciais do ensino fundamental. Daí, claro, começaremos problematizando por aqui: será que a formação oferecida até aquele momento, no que diz respeito ao tratamento dos conteúdos e do ensino da matemática, por exemplo, era tão diferente da atual, a ponto de não levantar as preocupações que são tão destacadas em âmbito nacional?

Acreditamos que o ensino de matemática passou despercebido, nesse processo de escuta, por haver, muitas vezes, um caráter embutido no curso que priorizava outras áreas de formação. Sabe aquelas "marcas" das quais falamos anteriormente? Os 34 anos de curso priorizando a formação de orientadores e administradores não hierarquizou as áreas, a ponto de silenciar outras que, naquele momento, não atendiam o perfil desejado de formação?

Priorizar áreas em detrimento de outras é uma coisa que fica ainda mais evidente, para nós, no momento que ouvimos as estudantes. Gabriela, por exemplo, comentando em sua entrevista, em tom de crítica, a respeito do número de disciplinas dentro do curso que são voltadas para a formação do Gestor. Segundo a aluna, muitas das referências e leituras propostas são semelhantes, uma vez que os pro- fessores possuem mesma base teórica e procedem de mesmas escolas de formação.

Por que pensamos isso e batemos nessa tecla de que as vozes, quanto à preocupação com a matemática e seu ensino, por exemplo, nesse processo de formação inicial, podem ter sido silenciadas? Em uma de minhas conversas com a Cármen, que acompanhou as reelaborações do PP de 2004 e 2007, enquanto docente do curso, ela relatou que, em uma das reuniões para tratar dessa questão, apontou a problemática da insuficiência de tempo para o trabalho com a matemática e a necessidade de ampliação de carga-horária. O que pode ter havido? Um "filtrar" das reinvindicações apresentadas para atender a um perfil de formação desejado, já que isso não aparece em nenhum momento no documento?

Vamos pensar um pouco mais sobre isso, criando um paralelo a partir das experiências que vivemos e trazer, também, as vozes das estudantes? Levando em consideração o que nos apresentam algumas estudantes, em suas falas, ${ }^{17}$ veremos que embora já existisse um reconhecer das dificuldades com a matemática e uma preocupação com esse aspecto na formação, ela passa a se tornar presente no momento em que aparece como disciplina a ser cursada. Temos aqui, portanto, um espaço de reflexão apropriado para pensar as questões que envolvem o ensino e a aprendizagem da matemática. Por que apropriado? Porque as estudantes parecem estar abertas para a discussão. Vejamos o que nos diz a Elisa, por exemplo.

No começo eu escolhi a Pedagogia por que era uma coisa que eu queria. A última coisa que eu pensei em ter contato foi com a matemática, embora tenha me passado pela cabeça, vagamente, que, como professora, eu teria que saber alguma coisa sobre esse conteúdo. Foi

17 Usaremos o termo "fala" todas as vezes que precisarmos nos referir aos dados presentes na entrevista narrativa. 
uma surpresa quando eu fui fazer a matrícula e finalmente estava lá "Matemática: Conteúdos e seu Ensino". Naquele momento eu fiquei apreensiva, porque como eu já relatei em outros momentos de meu diário, eu tenho uma dificuldade com a matemática. Então, foi uma surpresa e eu fui superando a cada aula.

Embora existissem dificuldades, isso fica evidente na fala da estudante - veja, caro leitor, que há certa espera, mesmo que não desejada, por essa disciplina? Observe que Elisa apresenta a palavra18 "finalmente", em sua narrativa. A leitura que fazemos, nesse momento, é que existia uma preocupação com esse aspecto da formação e que, em contrapartida, havia uma expectativa de que, nessa disciplina, as dificuldades sinalizadas por algumas estudantes fossem resolvidas; afinal, aponta Elisa: "como professora, eu teria que saber alguma coisa sobre esse conteúdo".

$\mathrm{Na}$ verdade, nessa mesma fala de Elisa, se nos ativermos a sua entrevista, ela destaca, na sequência do que apresentamos anteriormente, além do medo da própria matemática, um receio de que a disciplina, agora na graduação, se apresentasse como em seu período de estudante da educação básica. Mais uma vez, há uma expectativa de sanar as dificuldades deixadas pelo processo de escolarização básica. Ela percebe, no entanto, que "as coisas são apresentadas de uma forma muito diferente, né? Que não é a forma que a gente teve aula durante a nossa escolarização fundamental [...]".

Para algumas estudantes, como a Maria, por exemplo, algumas reflexões nascidas do contato com essa disciplina, na graduação, foram inevitáveis. Ela sinaliza que pensou, quando frustrada por sentir que não sabia matemática: "como eu vou ser capaz de ensinar uma coisa que nem eu sei?" Isso, de certo modo,

18 Larrosa Bondía (2002) nos alerta sobre a importância das palavras e que elas não aparecem por acaso nas narrativas. nos leva a refletir, mais uma vez, sobre uma expectativa da estudante para com a disciplina e de um revelar dificuldades que possui. Esperase, portanto, aprender matemática e sanar as dificuldades trazidas da escolarização.

Claro que uma maior preocupação com esse aspecto da formação só apareceria, de fato, durante ou após a vivência da disciplina "Matemática", uma vez que as estudantes tinham uma expectativa e que, só depois, saberiam se houve alguma correspondência com seus anseios. Apresentaremos, a seguir, alguns excertos que apontam para o que revelam as estudantes a esse respeito.

Gabriela: [...] Mas hoje eu acho que é importante e que precisariamos de mais disciplinas assim.

Elisa: [...] eu gostaria de ter outro semestre. Um é muito pouco para o tanto de possibilidade que a gente pode viver a matemática e seu ensino.

Emily: É... acho que o curso precisaria ter mais matemática. Agora, no final, que eu fiquei sabendo que tem uma ACIEPE que é ofertada nesse sentido. Mais um tempo trabalhando com isso seria interessante. Ela fez refletir... um tempo a mais faria colocar em prática outras coisas.

Perceba que para essas estudantes, após a vivência da disciplina, houve um reconhecer que o tempo destinado ao trabalho com a matemática e o seu ensino foi insuficiente. Por que será que na consulta realizada para reelaboração do PP, em 2007, as estudantes que haviam cursado a disciplina, na época, não levantavam essa questão? Talvez o grupo, naquele momento, não possuísse tais dificuldades e, caso existissem, o trabalho realizado pode ter possibilitado saná-las.

Hilda, por exemplo, durante a sua entrevista, nos relata que embora professora experiente e sem possuir dificuldades com a matemática, considera que é preciso "pensar que um semestre em um curso é muito pouco", mesmo 
para ela que vem de um Ensino Médio cursado no Magistério e ter feito o CMCM (Conteúdos Metodológicos de Ciências e Matemática).

A discussão que construímos até aqui buscou mostrar que a inquietude com a própria formação, no que diz respeito ao ensino e à aprendizagem da matemática, existe, atualmente, no curso, e isso se apresenta nos relatos e escritas das estudantes que participaram desta pesquisa. Longe de criarmos generalizações, pois não é isso que pretendemos. Assim, não nos entenda errado, caro leitor. Só nos preocupa o fato de que, na contramão do que tem sido discutido nas pesquisas, em âmbito nacional, como a realizada por Gatti (2010), essa questão, aflorada no momento desta investigação, não tenha figurado no documento, mesmo que a Cármen tenha nos apontado essa preocupação e sinalizado para o grupo, na época.

Outro ponto que merece atenção e que nasceu da leitura do Projeto Pedagógico é a realização de um estágio supervisionado, voltado para a alfabetização, ocorrer somente no 5o semestre do curso, sem um contato prévio com a disciplina "Matemática".19 Teria havido, durante a disciplina de alfabetização, o cuidado de discutir as particularidades do processo de alfabetização e letramento matemático?

Percebemos, em recorte analítico da pesquisa, publicado anteriormente, que a maioria das estudantes participantes deste estudo não conseguiu conceituar, no primeiro dia da disciplina "Matemática", o que seria a alfabetização matemática (SILVA; PASSOS, 2016a). A questão que se coloca: como elas realizaram o estágio nas escolas públicas de São Carlos e trabalharam com essa ciência, na perspectiva do letramento, sem conhecer do que se tratava? Acreditamos que a lógica pensada, no movimento de realização desse estágio, supervalorizava a

19 Essa discussão foi feita, anteriormente, como um recorte desta pesquisa, e publicada em eventos e revista científica (SILVA; PASSOS, 2016a; 2016b; 2016c). alfabetização em língua materna, desconsiderando todo um movimento feito pelo Ministério da Educação, em defesa da alfabetização, na perspectiva do letramento, com o Pacto Nacional pela Alfabetização na Idade Certa PNAIC, a partir de 2013, por exemplo.

Com a realização da entrevista narrativa, ${ }^{20}$ temos alguns relatos a esse respeito, originados quando questionamos algumas estudantes sobre isso. Vejamos, por exemplo, o que nos relata Emily.

Quando você vai fazer a disciplina de Alfabetização e Letramento vai achando que não terá que lidar com as questões da Matemática. Só que na sala de aula, no dia a dia, tinha a rotina e nessa rotina tem a Matemática. No caso, nesse estágio, a professora me deixou com um aluno que tinha dificuldades. Então na aula de Matemática as atividades [para esse aluno], por exemplo, eram outras. Então, ela que fazia aquelas continhas bem bobas mesmo. Daí eu o acompanhava. Então, eu não tive que ensinar ele. Ele estava do meu lado, ele demorava, ele contava no dedo e tudo. Eu ensinei sim, no sentido de ajudar, mas não era uma coisa que eu estava pensando: "ah, o que eu vou fazer com as crianças". E eu não tinha ainda pensado em problematizar isso, por que eu poderia, eu mesma, pensar em levar alguma coisa de casa. Nas outras aulas não, eu participava de uma forma mais efetiva, mas nessa aula, ela [professora] já vinha com o material e eu só ficava do lado dele, ajudando se precisasse. (silêncio)

A narrativa da estudante nos leva a pensar sobre o lugar que o "Estágio de Alfabetização" ocupa no processo de formação do professor que ensinará matemática para os anos iniciais. Percebemos que houve omissão em se pensar

20 A relevância das entrevistas narrativas na pesquisa qualitativa, como nos apresenta Weller e Zardo (2013, p. 133), "importa na contribuição que este instrumento fornece para a compreensão das estruturas processuais dos cursos de vida ou trajetórias dos sujeitos pesquisados" como destaca Apple (2005), fundamentando-se em Schutze (2011). Ainda segundo os referidos autores, "o ato de rememorar e a narração da experiência vivenciada de forma sequencial permitem acessar as perspectivas particulares de sujeitos de forma natural". 
a alfabetização matemática na disciplina. A estagiária, futura professora, serviu de apoio para o trabalho da professora da turma, acompanhando alunos que apresentavam dificuldades em matemática, repetindo práticas mecanizadas, com algoritmos, o que a fez concluir: "eu não tive que ensinar nada". Nas palavras angustiadas de Emily, está nítida a lacuna na formação que não the permitiu propor algo favorável à aprendizagem matemática do aluno, pois, até então, a alfabetização matemática não tinha sido discutida no curso de Pedagogia. Isso é recorrente no relato apresentado por Gabriela.

O meu estágio não foi de alfabetização, foi de Matemática na verdade. Por que as aulas que eu acompanhei não foram de alfabetização, foram de Matemática. Eu me deparei na sala, foi um 5 은 ano que eu peguei, em uma escola de periferia, com um público mais carente. Dentro da sala de aula tinha um aluno, que se chamava Marcos e tinha baixa visão, ele usava um óculos superpotente, e por ser um aluno problema para a professora os estagiários ficavam ao seu lado. Não fazia sentido algum a gente ir [para uma sala de 5o ano] enquanto estagiário de alfabetização. $E$ foi um aluno que eu acabei acompanhando durante esse estágio de alfabetização. E, como os dias que eu podia ir à escola, não eram só os dias de [aulas de] Português eu passei por muitas disciplinas, principalmente a Matemática. Por que os dias que eu ia tinha metade do dia de Matemática. E eu acompanhei esse aluno, principalmente. Foi um processo interessante de ver que eu trazia soluções. Inclusive na disciplina de "Matemática: conteúdos e seu ensino", eu via alguma coisa que eu falava: "ah isso eu fiz com Marcos". Então algumas coisas de jogos, jogos criados ali dentro da própria atividade. Isso que eu falei da professora, do contar com o dedo. Mas é um trabalho bem dificil, por que é ensinar a um aluno que já tem dificuldade de aprendizagem.

Nesse relato percebemos que a estudante também foi incumbida de acompanhar um aluno com defasagem em matemática. Obser- va-se ainda que estagiar em uma sala de $5 \underline{0}$ ano, de certa maneira, desconfigura as características necessárias para a realização de um “Estágio de Alfabetização", uma vez que o 5o ano não faz parte do ciclo de alfabetização (10 ao 3 ㅇ ano).

Observem que a estudante, ao refletir sobre a experiência que teve durante o estágio, reconhece que muitas estratégias apresentadas durante a disciplina foram usadas por ela com o Marcos. o jogo, por exemplo, foi usado para trabalhar com esse aluno que apresentava dificuldades de aprendizagem. A opção por utilizar determinado instrumento metodológico sinaliza, sobretudo, o reconhecer de seu potencial pedagógico.

São esses os pontos iniciais, considerados por nós cruciais na leitura, que queríamos problematizar nesse momento. 0 nosso intuito com este artigo é ampliar o olhar sobre assas questões, e não apresentar uma lista de resposta aos questionamentos que são feitos.

\section{As competências e habilidades apresentadas e o que nos revelam sobre a formação lúdica e matemática desses futuros professores}

No Projeto Pedagógico é listada uma série de competências e habilidades, selecionadas dentre as indicadas pela Comissão de Especialistas de Pedagogia/MEC, entendidas como essenciais a serem desenvolvidas no decorrer do curso. Para possibilitar o seu desenvolvimento, o curso foi dividido em três dimensões, segundo o documento, organicamente relacionadas: Docência, Gestão Democrática e Pesquisa. Se nos ativermos a essa lista com um olhar mais analítico e não perdendo de foco o objetivo ${ }^{21}$

21 Nesse sentido, orientados pelos objetivos da pesquisa e pelas experiências vivenciadas, olharemos para essa questão, na tentativa de perceber como a 
da escrita deste texto, perceberemos o que se espera, de fato, desse futuro pedagogo.

Podemos começar pelas questões de ludicidade? Como o PP do curso de Pedagogia da UFSCar traz essa questão? Para dar início a esse voltar, vamos olhar para o documento e nos reportar à lista de 17 competências e habilidades colocadas. Notamos que apenas em dois momentos há elementos que podem nos remeter às questões da ludicidade: "propondo respostas criativas" e "compreensão e valorização de diferentes linguagens". Em nenhum momento, o termo ludicidade ou lúdico é apresentado. 0 documento encontra-se na contramão das diretrizes curriculares para o curso de Pedagogia, que apresenta o termo algumas vezes. Percebemos que, no processo de construção do PP, esse perfil pode ter sido desconsiderado ou substituído pelo termo criatividade. Será?

Nesse caso, nos cabe destacar que existe uma diferença conceitual entre o "ser lúdico" e o "ser criativo", embora em alguns momentos seja possivel realizar algumas aproximações. Caso essa tentativa de igualá-las tenha sido feita nesse documento, pontuamos que entendemos tais expressões como duas coisas distintas. Definiremos, nesse momento, o que entendemos por lúdico e em seguida traremos a ideia da criatividade para, depois, pontuar os motivos de não os entender de forma semelhante.

Em uma análise etimológica, percebemos, como apontam Santos e Cruz (2011, p. 9), que a palavra lúdico em língua portuguesa originouse do latim ludus e significa brincar. Incluemse, assim, nesse brincar, os jogos, brinquedos e divertimentos, e ainda a conduta daquele que joga, que brinca e que se diverte. Enten-

ludicidade e a formação do professor que ensinará matemática nos anos iniciais estão postas no Projeto Pedagógico do curso; o que se apresenta nos demais documentos que serviram de base para ele e como todo esse movimento formativo, de alguma forma, foi significado pelas estudantes. demos, nesse momento, que o sujeito lúdico é aquele que brinca. Apresentar a ludicidade nessa perspectiva, enquanto parte necessária para a construção da identidade docente, é esperar que esse futuro professor brinque e se divirta enquanto conduz o processo de ensino e possibilite uma experiência semelhante para seus alunos.

Já a etimologia da palavra criatividade, em língua portuguesa, nos remete ao termo criar, do latim creare, que significa, como nos apresentam Pereira et al (1999, p. 4), “dar existência, sair do nada, estabelecer relações até então não estabelecidas pelo universo do indivíduo, visando determinados fins". Fica claro, na definição apresentada e com a qual concordamos, nesse momento, que o sujeito criativo é aquele que cria e estabelece relações antes não pensadas, por exemplo.

Depois desse olhar sobre as duas palavras, fica claro para você, querido leitor, que apresentá-las como parte das habilidades e competências requeridas em um curso de formação inicial implica movimentos formativos diversos? Consegue perceber, conosco, que ambas tratam de aspectos diferentes? Acreditamos que as questões da criatividade não dão conta, sozinhas, da formação lúdica ${ }^{22}$ do futuro professor.

Tudo isso nos leva a inferir que a não preocupação com as questões da ludicidade, em relação ao curso pesquisado, começa no momento de pensar essas habilidades e competências que, em contrapartida, conduziriam à construção do currículo de outra maneira.

Lembra-se, caro leitor, do que escrevi anteriormente sobre o não uso do termo ludicidade no PP do curso de Pedagogia da UFSCar, mes-

22 Entendemos, nesse momento, partindo do que nos apresentam Santos e Cruz (2011), que a formação lúdica proporciona aos futuros educadores vivências lúdicas, experiências corporais, que se utilizam da ação, do pensamento e da linguagem, tendo no jogo, na brincadeira e nas demais ferramentas com potencial lúdico suas fontes dinamizadoras. 
mo quando as Diretrizes direcionavam para algo diferente? 0 Art. 6o das Diretrizes Curriculares para o curso de Pedagogia, que serviu de base para a construção do Projeto Pedagógico, observa que a estrutura do curso, respeitadas a diversidade nacional e a autonomia pedagógica das instituições, constituir-se-á de:

I - um núcleo de estudos básicos que, sem perder de vista a diversidade e a multiculturalidade da sociedade brasileira, por meio do estudo acurado da literatura pertinente e de realidades educacionais, assim como por meio de reflexão e ações críticas, articulará:

\section{[...]}

e) aplicação, em práticas educativas, de conhecimentos de processos de desenvolvimento de crianças, adolescentes, jovens e adultos, nas dimensões fisica, cognitiva, afetiva, estética, cultural, lúdica, artística, ética e biossocial;

\section{[...]}

i) decodificação e utilização de códigos de diferentes linguagens utilizadas por crianças, além do trabalho didático com conteúdos, pertinentes aos primeiros anos de escolarização, relativos à Língua Portuguesa, matemática, Ciências, História e Geografia, Artes, Educação Física;

\section{[...]}

k) atenção às questões atinentes à ética, à estética e à ludicidade, no contexto do exercício profissional, em âmbitos escolares e não-escolares, articulando o saber acadêmico, a pesquisa, a extensão e a prática educativa; [...]. (BRASIL, 2006, p. 3, grifos nossos)

Esse documento, pelas leituras que fizemos, indica a ludicidade enquanto uma dimensão que precisa ser respeitada e considerada no processo de formação. Mas não fica claro, em nenhuma passagem, por exemplo, o que se entende por esse termo e quais as implicações dele no processo de construção da identidade do futuro pedagogo.

Quando as Diretrizes apresentam a ludicidade enquanto uma dimensão que precisa ser considerada no núcleo de estudos básicos do curso, entendemos que olhar para essa questão nos remete a perceber que existem algumas especificidades que caracterizam essa dimensão lúdica, no contexto do exercício profissional.

Partimos do pressuposto, respaldando-nos em Huizinga (2012), de que a ludicidade é necessária ao desenvolvimento do ser humano e, por isso, o autor o classifica como homo ludens. Contudo, embora também seja uma necessidade humana, o processo de ensino-aprendizagem raramente se refere ao prazer $^{23}$ ou à felicidade como meta a ser alcançada. Dessa reflexão, podemos inferir que há um grande hiato entre aprendizado e prazer. Nesse sentido, olhar para as questões da ludicidade contribuiria muito positivamente (SILVA, 2014).

Como nos apresentam Santos e Cruz (2011), é importante considerar que a formação do educador passa por ambiguidades e paradoxos que nunca são efetivamente dissipados. Disso resulta quase sempre dificuldades no campo da prática pedagógica. As autoras ainda asseveram que os cursos de licenciatura têm recebido fortes críticas pela ineficiência quanto à formação de professores, principalmente pelo despreparo para atender às necessidades das escolas e por não compreenderem a criança como um ser histórico-social responsável e capaz de construir seu próprio conhecimento. Com essa crítica, apresentam a ludicidade na perspectiva de melhorar a formação e entender o sujeito e suas especificidades.

23 Retomei algumas leituras e percebi que alguns autores discutem o lugar do desprazer da ludicidade e o apresentam como característica. Em Kishimoto (1993, p. 7), por exemplo, ao assinalar pontos comuns que interligam a grande família jogo: "liberdade de ação do jogador ou caráter voluntário e episódico da ação lúdica; o prazer (ou desprazer), o 'não sério' ou o efeito positivo; as regras (implícitas ou explícitas); a relevância do processo de brincar (o caráter improdutivo); a incerteza de seus resultados; a não literalidade ou a representação da realidade; a imaginação e a contextualização no tempo e no espaço". 
Durante a entrevista que realizamos no primeiro semestre de 2017, tratamos a questão da ludicidade e fizemos alguns questionamentos a esse respeito. Uma coisa que cabe considerar é que, em algumas falas, as estudantes revelam que apenas nas disciplinas de "Corpo e Movimento", "Educação Infantil" e "Matemática" a ludicidade foi trabalhada.

Como nos apresentou Gabriela, durante a entrevista, a ludicidade aparece na disciplina de "Matemática" "porque a Cármen decidiu trazer, porque não faz parte... pode ser que outros alunos nem tenham tido isso". Pela fala da estudante, as outras duas disciplinas seriam, realmente, espaços em que essa discussão naturalmente apareceria. Na disciplina de "Educação Infantil", sobretudo, por tratar do desenvolvimento do bebê, o lúdico aparece como interação.

Acreditamos que as percepções das estudantes em relação à disciplina ser um espaço de discussão da ludicidade resultaram da inserção da pesquisa no movimento da aula. Realmente não é objetivo da disciplina "Matemática", segundo propõe o próprio PP, discutir a ludicidade. Minhas intervenções, ao longo das estratégias formativas propostas, intencionavam pontuar essas questões, quando apareciam.

Inferimos, partindo do olhar para o PP do curso de Pedagogia da UFSCar e das experiências reveladas pelas estudantes, que houve um negligenciar da ludicidade na construção das competências e habilidades. Como a formação lúdica não é uma preocupação do curso, percebemos que poucas disciplinas, uma delas, na verdade, foi posta para cumprir com esse papel. As demais trazem a discussão da ludicidade como secundária ou apareceram por opção do professor que trabalhou com a disciplina naquele momento.

No caso da disciplina "Matemática", a discussão da ludicidade, além dos textos que traziam volta e meia essa questão, ${ }^{24}$ aparece, principalmente, como metodologia. Assim, há uma articulação entre este e os conteúdos matemáticos, afinal, como dissemos em aula, não conseguiremos transitar bem no ensinar matemática, se não conhecermos os conteúdos que serão trabalhados.

Agora o convido, caro leitor, para abordarmos algumas questões que envolvem o ensino de matemática. Para isso, portanto, olhemos, inicialmente, para o que a lista de habilidades e competências apresenta a esse respeito. Vamos lá?

Pelo menos em três passagens, conseguimos inferir que, direta ou indiretamente, há uma preocupação com as questões que envolvem o domínio do conteúdo. Por exemplo: "planejar intervenções pedagógicas", “dominando os conteúdos básicos relacionados às áreas/disciplinas de conhecimento" e "planejar, desenvolver e avaliar aulas, com domínio de conteúdo e de conhecimento pedagógico dos conteúdos".

Percebemos, nesse sentido, que o curso apresenta como preocupação para a formação dos futuros professores o domínio com os conteúdos básicos relacionados às diferentes áreas de conhecimento. Nesse caso, esses estudantes precisariam concluir o curso dominando os conteúdos matemáticos. Mas é isso que acontece?

Maria: Que eu pensei: "como eu vou ser capaz de ensinar uma coisa que nem eu sei?" Que, por exemplo, divisão, que eu já percebi que eu não sei fazer. Então, foi uma coisa de eu ficar pensando: "será que é falta de exercitar?" Porque eu não faço isso. Ou será que é por que eu não sei. Eu percebi que é muito dificil resgatar como você aprendeu para você ensinar tal pessoa. Por exemplo: "ah, eu sei fazer divisão. E qual é o processo passo a passo? Eu já esqueci, só

24 Era nesses momentos, caro leitor, que eu aproveitava e explorava esses pontos que considero importantes na formação lúdica do futuro professor. 
sei o resultado final. E aquela criança que ainda vai aprender?" Então isso foi uma coisa que me deixou um pouco frustrada na disciplina por que eu fiquei pensando: "de onde eu vou tirar ideia, onde eu vou resgatar isso, se é uma coisa que eu não sei fazer".

$\mathrm{Na}$ fala apresentada anteriormente, percebemos que algumas dificuldades conceituais se mantiveram, mesmo após o trabalho realizado na disciplina. Isso é revelado também por Elisa, em algumas passagens de sua entrevista. Ela, a Maria, continua tendo dificuldades com a divisão e projeta isso como reflexão para sua futura prática: "como eu vou ser capaz de ensinar uma coisa que nem eu sei?".

Assim como em relação à percepção que possuem sobre o "ser professor", é fato que muitos estudantes trazem marcas das experiências com a matemática e as ressignificam, a partir das vivências que são propiciadas durante o curso de formação inicial. A maioria das estudantes, por exemplo, participantes da pesquisa, sinaliza logo na escrita da narrativa inicial, o medo da matemática e o quanto acha não saber da mesma para ensiná-la.

Durante a entrevista, por exemplo, percebemos que algumas falas mudam de tom e as dificuldades, ou parte delas, passam a figurar no passado. Embora reconheçamos que é pouco tempo para o trabalho, sabemos que o que é feito contribui de alguma forma para isso.

Emily: [...] Quando a disciplina começou a nos fazer refletir eu me perguntei: "mas por que eu tinha dificuldade nisso?" É porque eu não entendia. A partir do momento que eu começo a entender vou me aprofundar e querer me apropriar ainda mais desses conhecimentos, vai ser uma questão de superar as dificuldades, sabe? E isso, com certeza, ajudou em minha formação, porque ai eu penso: "será que eu quero proporcionar que tipo de aprendizagem com a Matemática para meus alunos? De uma forma positiva ou negativa?" Então, na minha formação, implicou muito isso. Vou pensar muito bem antes de trazer alguma atividade, para que não aconteça o que aconteceu comigo. Porque eu já tinha dificuldade e dai parece que era um reforço negativo. Toda vez que eu falava "eu odeio Matemática" ficava pior.

Elisa: [...] Depois da disciplina a gente consegue enxergar um pouco mais. Antes eu não queria nem ouvir falar da Matemática, do ensino da Matemática ou algo do tipo. Acho que o que a disciplina traz, trouxe um pouco pelo menos para mim, que tenho essa dificuldade, é de você enxergar as coisas de forma diferente, né? Que tem jeito, que tem outras possibilidades, que você não precisa só usar a lousa, que você não pode também deixar o aluno só passar por aquilo, pois ele vai precisar daquilo depois.

Algumas estudantes apresentam dificuldades conceituais para o trabalho com essa ciência. Fica claro, e isso está presente nos diários e entrevistas dessas alunas, que essas dificuldades têm origem em sua escolarização básica, por diferentes motivos e em diferentes momentos. A partir do momento em que reconhecem que não sabem, buscam, na disciplina, sanar esse problema, mesmo que parcialmente, pois, para elas, é um fator que pode interferir no ensino que proporcionarão a seus futuros alunos.

Perceba, então, leitor, que, nesse momento, mesmo que algumas delas não se reconheçam enquanto futuras professoras, há uma preocupação com uma prática profissional futura, que algumas delas sinalizam, conscientemente, não quererem assumir? Elas estão, pelo contexto de sua história de vida e pelo que promove a disciplina, mergulhadas em um espaço que põe a docência como centro do pensar a formação. Daí esse perfil passa a ser um foco de reflexão.

Nesse sentido, Serrazina (2002) salienta que, além dos conteúdos matemáticos, é importante, durante a formação inicial, permitir que os futuros professores desenvolvam uma atitude investigativa e questionadora em ma- 
temática. Nas falas das estudantes, apresentadas a seguir, vemos isso.

Emily: Foi. Com a matemática dessa forma sim. Apesar de que eu sei que tem ACIEPE [Atividades Curriculares de Integração Ensino Pesquisa e Extensão] e essas coisas, mas é assim, eu não consegui ir atrás. Eu comecei a pensar criticamente, tipo caiu a ficha do que estava acontecendo, depois da disciplina.

Emily: A parte reflexiva da disciplina nos ajudou muito mais no "como eu vou buscar isso agora". $E$ ai a ficha caiu. Nesse momento ficou evidente para mim: "Eu sou alguém que não gosta de matemática, mas eu vou precisar ensinar matemática e ai o que eu faço com isso?" Ai eu tive que pensar o porquê eu não gostava, os motivos de ter deixado de gostar em algum momento e mudar essa postura. Então foi na disciplina mesmo.

Elisa: Depois da disciplina a gente consegue enxergar um pouco mais. Antes eu não queria nem ouvir falar da matemática, do ensino da matemática ou algo do tipo. Acho que o que a disciplina traz, trouxe um pouco pelo menos para mim, que tenho essa dificuldade, é de você enxergar as coisas de forma diferente, né? Que tem jeito, que tem outras possibilidades, que você não precisa só usar a lousa, que você não pode também deixar o aluno só passar por aquilo, pois ele vai precisar daquilo depois.

Como várias pesquisas apontam, Almeida (2009), Taques Filho (2012), Rocha (2005), muitos estudantes concluem o curso de Pedagogia sem o domínio dos conhecimentos matemáticos, e aqui também observamos esse sentimento. Isso, de certo modo, nos leva a pensar que muitos cursos não têm se preocupado com os conteúdos da forma como deveriam e como é esperado, enquanto competência e habilidade requeridas. Vejamos alguns pontos do PP do curso da UFSCar que nos dão a entender isso.

No que tange ao ensino de matemática, em relação ao que apresenta o PP do curso, inferimos que existe uma preocupação manifesta no documento quanto à necessidade de domínio do conteúdo. Isso foi apresentado em duas das habilidades e competências. Infelizmente, pela organização dada ao currículo, não percebemos como isso pode ser, verdadeiramente, efetivado. Como as estudantes, em relação aos conceitos matemáticos, poderiam conseguir avançar no tão curto tempo que é destinado a isso, ainda continua sendo uma indagação, após esse estudo.

\section{Algumas considerações}

Gostaria que você, leitor, não lesse esta seção de considerações a respeito da experiência vivenciada, em um tom de generalização. Tudo que dissermos aqui foi envolto em um contexto, situado em um tempo, com um público específico e a partir da vivência de uma série de experiências de processos formativos. Isso nos autoriza, sobretudo, a falar desse público e dessas experiências, de uma forma particular. E é justamente isso que faremos aqui.

Foi a partir do olhar para o Projeto Pedagógico, por exemplo, que de certo modo percebemos que há, até esse momento, uma supervalorização de um perfil específico de formação. Pela história do curso e sua ligação, desde a sua criação, com as questões de orientação e administração escolar, e pelo que nos apresentaram as estudantes, notamos que se prioriza um determinado aspecto da formação em detrimento de outros.

Ao longo de nosso olhar para o PP, fomos identificando características embutidas no curso que priorizavam essas outras áreas, diferentes da do docente. Uma maior preocupação ou olhar mais atento à formação do professor que ensinará matemática nos anos iniciais e a sua formação lúdica, por exemplo, foram silenciadas do documento.

Em relação à ludicidade, por exemplo, percebemos que o documento se encontra na contramão das Diretrizes Curriculares para o 
Curso de Pedagogia. Na construção do Projeto Pedagógico, esse aspecto da formação foi desconsiderado. A ausência do termo ludicidade ou algo que remeta a isso, no documento, nos fez pensar que a não preocupação com as questões da ludicidade começa no momento de pensar as habilidades e competências esperadas desse futuro pedagogo e conduz para percursos de formação e construção de currículos que não a valorizam.

Percebemos que a preocupação com a formação do professor que ensinará matemática é diminuta. Embora exista, muitas vezes, um esforço enorme do formador para possibilitar uma aproximação dos estudantes com essa ciência e um ressignificar das dificuldades e medos que são trazidos do ensino básico, o pouco tempo destinado a essa disciplina impossibilita que muito seja feito. Muitas estudantes, infelizmente, concluem o curso sem o domínio dos conhecimentos matemáticos. Algumas falas apresentadas ao longo da pesquisa, e principalmente nas entrevistas que aconteceram no último ano de curso, nos remetem a pensar isso, sobretudo nos relatos de Elisa e Maria.

Pensamos: será que essas questões, do conhecimento matemático e de outras áreas do conhecimento, estariam presentes como parte da pontuada desarticulação entre teoria e prática? Por um momento pensamos nisso. Mas, pelas ações e pela forma como a matriz curricular foi construída, percebemos que não se avançou muito nesse sentido, tendo em vista a antiga proposta. Essa desarticulação entre teoria e prática, mesmo após a reformulação, se manteve. Identificamos indícios, ainda presente, da mesma estrutura que havia sido criticada.

Um exemplo dessa desarticulação está no momento de apresentar um estágio de alfabetização antes da vivência da disciplina de "Matemática". Percebemos que houve uma omis- são em se pensar a alfabetização matemática na disciplina "Alfabetização". Isso foi notado na própria fala de Emily. Teve aluna, como a Gabriela, que fez o estágio de alfabetização em um ano que não pertencia ao ciclo de alfabetização.

A partir das vivências das estudantes com a disciplina "Matemática", por exemplo, embora com o pouco tempo que lhe é destinado, houve uma ressignificação na forma como viam a matemática e o vislumbrar de seu ensino. Temos agora, como nos revelam as próprias estudantes, futuras professoras dispostas a aprender e a tentar fazer um ensino diferente daquele que tiveram.

Até para as estudantes que não objetivavam seguir a carreira docente, há uma preocupação, manifesta em suas narrativas, com sua futura prática como professoras, mesmo em se tratando apenas de uma projeção. Mas por que algumas estudantes não querem, ao final do curso, serem professoras? Percebemos que para essas estudantes, Gabriela, Elisa e Maria, que revelam não querer assumir a docência como atividade profissional, questões como os baixos salários, os planos de carreira e as condições de trabalho pontuam muito negativamente.

Em relação ao que essas estudantes concebem sobre ludicidade, percebemos que, desde o início do curso, esse conceito foi sendo (re) significado. Elas destacam que em três disciplinas apenas essa questão foi trabalhada e pontuam a "Matemática" como uma delas. "Corpo e movimento" e "Educação Infantil" foram as outras duas e, a segunda dessas, não conseguiu, pelo nosso olhar para a proposta e o que nos revelaram as estudantes, cumprir com o que era proposto na ementa e no plano de trabalho presente no PP.

Elas relatam, em suas entrevistas, que a forma como percebem a ludicidade hoje e a percebiam antes do início do curso é muito di- 
ferente. Para muitas delas, houve um transpor da ludicidade como jogo e brincadeira apenas para uma percepção que o concebe de forma mais ampla, entendendo a subjetividade que há em sua tomada e a importância de que a própria matemática seja percebida como lúdica. Encontramos estudantes, como Elisa, que partiu da ideia de que o lúdico era algo que não possibilitava aprendizagem, por exemplo. As estudantes, portanto, mesmo o curso não apresentando a ludicidade como parte das habilidades e competências ou expressando uma preocupação com esse aspecto da formação, ressignificaram, ao longo do curso, o que concebiam.

O processo de escrever sobre os encontros e retomar, da própria história de vida, como se deu essa construção da relação com a matemática, possibilitou desmistificar o medo e algumas dificuldades que as estudantes possuíam. Algumas estudantes assumiram a prática de escrita em diários, após a pesquisa, como algo que fará parte do seu fazer pedagógico e do pensar a sua formação.

Esses foram alguns pontos que este artigo nos permitiu ampliar. Agora, depois dele, sabemos o que propusera o curso de Pedagogia e como algumas estudantes significaram as experiências que foram vividas.

\section{Referências}

ALMEIDA, M. B. A formação inicial de professores no curso de Pedagogia: constatações sobre a formação matemática para a docência nas séries iniciais do Ensino Fundamental. 2009. 177 f. Dissertação (Mestrado em Educação para a Ciência e a Matemática) - Programa de Pós-Graduação em Educação para Ciências e Matemática, Universidade Estadual de Maringá, UEM, Maringá, PR, 2009. Orientadora: Maria das Graças de Lima. Disponivel em: <http:// www.pcm.uem.br/?q=node $/ 80 \& \min =50 \& \operatorname{man}=60 a>$. Acesso em: 04 abr. 2019.

APPLE, M. La entrevista autobiográfica narrativa: fundamentos teóricos y la praxis del análisis mostrada a partir del estudio de caso sobre el cambio cultural de los Otomíes en México. Forum: Qualitative Social Research, Mexico, v. 6, n. 2, p. 1-35, mai. 2005.

BRASIL. Parecer CNE/CP no 09, de 08 de maio de 2001. Institui as diretrizes curriculares nacionais para a formação de professores da educação básica, em nivel superior, curso de licenciatura, de graduação plena. Brasília, DF: MEC, 2001.

Ministério da Educação. Diretrizes Curriculares Nacionais para os Cursos de Pedagogia. ParecerCP/CNE 05_2005, homologação publicada no DOU 15/05/2006, Seção 1, p. 10. Parecer CP/CNE 03_2006, homologação publicada no DOU 11/04/2006, Seção 1, p. 19. Resolução CP/CNE 01/2006, publicada no DOU 16/05/2006.

CLANDININ, D. J.; CONNELLY, F. M. Pesquisa narrativa: experiência e história em pesquisa qualitativa. Uberlândia, MG: EDUFU, 2015.

CRECCI, V. M. Desenvolvimento profissional de educadores matemáticos participantes de uma comunidade fronteiriça entre escola e universidade. Campinas, SP: Editora da Unicamp, 2016.

CURY, H. N. Concepções e crenças dos professores de matemática: pesquisas realizadas e significado dos termos utilizados. Bolema - Boletim de Educação Matemática, Rio Claro, v. 12, n. 13, p. 29-43, 1999.

GATTI, B. Formação de professores no Brasil: características e problemas. Educação e Sociedade, Campinas, v. 31, n. 113, p. 1355-1379, out./dez. 2010.

HUIZINGA, J. Homo ludens: o jogo como elemento da cultura. 7. ed. São Paulo: Perspectiva, 2012.

KISHIMOTO, Tizuko M. Jogos infantis: o jogo, a criança e a educação. Petrópolis, RJ: Vozes, 1993.

LARROSA BONDÍA, J. Notas sobre a experiência e o saber de experiência. Revista Brasileira de Educação, Rio de Janeiro, v. 2, n. 19, p. 21-28, jan./abr. 2002.

MAFFIOLETTI, L. D. A. Reflexões sobre os fundamentos do método (auto)biográfico: inventando relações. In: BRAGANÇA, I. F. D. S.; ABRAHÃO, M. H. M. B.; FERREIRA, M. S. (Orgs.). Perspectivas epistêmico- 
metodológicas da Pesquisa (auto)biográfica. Curitiba: Editora CRV, 2016. p. 51-66.

NÓVOA, A. Os professores e sua formação. Lisboa: Dom Quixote, 1992.

OLIVEIRA, R. M. M. A. Narrativas de formação: aspectos da trajetória como estudante e experiências de estágio. Interacções, Lisboa, v. 7. n. 18, p. 229-245, 2011.

PALMA, R. C. D. D.; MOURA, A. R. L. D. Formação inicial de professores e a produção de sentidos sobre 0 aprender e ensinar matemática. Revista Educação Pública, Cuiabá, v. 21, n. 47, p. 639-659, dez. 2012.

PEREIRA, B.; MUSSI, C.; KNABBEN, A. Se sua empresa tiver um diferencial competitivo, então comece a recriá-lo: a influência da criatividade para o sucesso estratégico organizacional. In: ENANPAD, 22., Foz do Iguaçu, 1999. Anais... Foz do Iguaçu: ANPAD, 1999.

PIMENTA, S. G. Formação de professores - Saberes da docência e identidade do professor. Revista Faculdade de Educação, São Paulo, v. 22, n. 2, p. 72-89, jul. 1996.

PIMENTA, S. G. Formação de professores: identidade e saberes da docência. In: PIMENTA, S. G. (Org.). Saberes pedagógicos e atividade docente. São Paulo: Cortez, 1999. p. 15-34.

ROCHA, M. S. Professores polivalentes das séries iniciais do Ensino Fundamental: concepção da formação e do ensino de Matemática. 2005. 269 f. Dissertação (Mestrado em Educação) - Programa de Pós-Graduação em Educação, Universidade Católica Dom Bosco, Campo Grande, MS, 2005. Disponivel em: <http://site.ucdb.br/public/md-dissertacoes/ 7945-Professorespolivalentes-das-series-iniciaisdo-ensino-fundamental-concepcao-da-formacao -e-doensino-de-matematica.pdf>. Acesso em: 01 abr. 2019.

SANTOS, S. M. P.; CRUZ. D. R. M. O. 0 lúdico na formação do educador. 9. ed. Petrópolis, RJ: Vozes, 2011.

SÃO CARLOS. Resolução no 315/97-CEPE, de 03 de outubro de 1997, do Conselho de Ensino e Pesquisa da Universidade Federal de São Carlos. Diário Oficial da União, 1997.
Projeto Pedagógico do Curso de Licencia-

tura em Pedagogia. Adequado à Resolução CNE/CP №. 01, de 15 de maio de 2006 e Aprovado no Conselho de Graduação, em 12 de dezembro de 2011. São Carlos: UFSCAR, 2012.

SERRAZINA, M. D. L. M. A formação para o ensino de matemática: perspectivas futuras. In: SERRAZINA, M. D. L. M. (Org.). A formação para o ensino da matemática na educação pré-escolar e no $1^{\circ}$ ciclo do ensino básico. Porto: Porto Editora, 2002. p. 9-19.

SILVA, A. J. N. D. A formação inicial do educador matemático: o "x" da questão. In: SÁ, A. V. M. D. et al. (Orgs.). Ludicidade e suas interfaces. Brasília, DF: Liber Livros, 2013. p. 159-172.

A ludicidade no laboratório: considerações sobre a formação do futuro professor de matemática. Curitiba: Editora CRV, 2014.

SILVA, A. J. N. D.; PASSOS, C. L. B. Ensinar matemática: o que dizem as narrativas sobre a formação e futura prática profissional. In: CONGRESSO NACIONAL DE FORMAÇÃO DE PROFESSORES (CNFP), 3.; CONGRESSO ESTADUAL PAULISTA SOBRE FORMAÇÃO DE EDUCADORES (CEPFE), 13., 2016a, Águas de Lindóia. Anais... Águas de Lindóia: Unesp, 2016a. p. 56-60.

SILVA, A. J. N. D.; PASSOS, C. L. B. O diário reflexivo do professor que ensinará matemática nos anos iniciais: o que revelam sobre a formação e futura prática profissional. In: CONGRESSO INTERNACIONAL DE PESQUISA (AUTO)BIOGRÁFICA, 7., 2016b, Cuiabá. Anais do Congresso Internacional de Pesquisa (auto)Biográfica. Cuiabá: UFMT, 2016b. p. 80-92.

SILVA, A. J. N. D.; PASSOS, C. L. B. P. Querido diário: o que dizem as narrativas sobre a formação e futura prática do professor que ensinará matemática nos anos iniciais. HIPÁTIA - Revista Brasileira de História, Educação e Matemática, Campos do Jordão, v. 1, n. 1, p. 46-57, dez. 2016c.

TAQUES FILHO, L. S. A formação matemática de futuros pedagogos-professores das séries iniciais do Ensino Fundamental. 2012. 141 f. Dissertação (Mestrado em Educação) - Programa de Pós-Graduação em Educação, Pontificia Universidade Católica, PUC -PR, Curitiba, 2012. Orientadora: Neuza Bertoni Pin- 
to. Disponivel em: <http:// www.biblioteca.pucpr.br/ tede/tde_busca/arquivo.php?codArquivo=2348>. Acesso em: 01 abr. 2019.

WELLER, W.; ZARDO, S. P. Entrevista narrativa com especialista: aportes metodológicos e exemplifica- ção. Revista da FAEEBA - Educação e Contempora-

neidade, Salvador, v. 22 , n. 40, p. 131-143, jul./dez. 2013.

Recebido em: 30.01.2019

Aprovado em: 30.03.2019

Américo Junior Nunes da Silva é Mestre em Educação pela Universidade de Brasília (UnB) e Doutor em Educação pela Universidade Federal de São Carlos (UFSCar). Integra os Grupos de Estudos e Pesquisas em Educação Matemática (CNPq/UFSCar), Aprendizagem Lúdica: Pesquisas e Intervenções em Educação e Desporto (CNPq/UnB) e Formação de Professor e Currículo (CNPq/Uneb). Professor da Universidade do Estado da Bahia, Departamento de Educação do Campus VII, Senhor do Bonfim. e-mail: amerjun2005@hotmail.com

Avenida da Integração, 685. Premium Residence, apto. 103, bloco 01. Vila Eduardo. Petrolina, PE. CEP: 56328-010. Telefone (16) $99437-3434$

Cármen Lúcia Brancaglion Passos é Mestre em Educação: Metodologia de Ensino (Unicamp), Doutora em Educação: Educação Matemática (Unicamp). Realizou Pós-Doutorado na Faculdade de Ciências da Universidade de Lisboa (2008) e na Faculdade de Educação na USP (2016-2017). Professora Titular da Universidade Federal de São Carlos (UFSCar), Departamento de Teorias e Práticas Pedagógicas. Coordenou o PPGE UFSCar (2010 a 2015). Coordena o Grupo de Estudos e Pesquisas em Educação Matemática (GEM) na UFSCar. Pesquisadora do grupo PRAPEM/GEPFPM na Unicamp. Bolsista CNPq Produtividade. e-mail: carmenpassos@gmail.com

Av. José Bonifácio, 916, apto. 51, Jardim Flamboyant, Campinas, SP. CEP: 12092-305. Telefone (19) 99292-7363. 